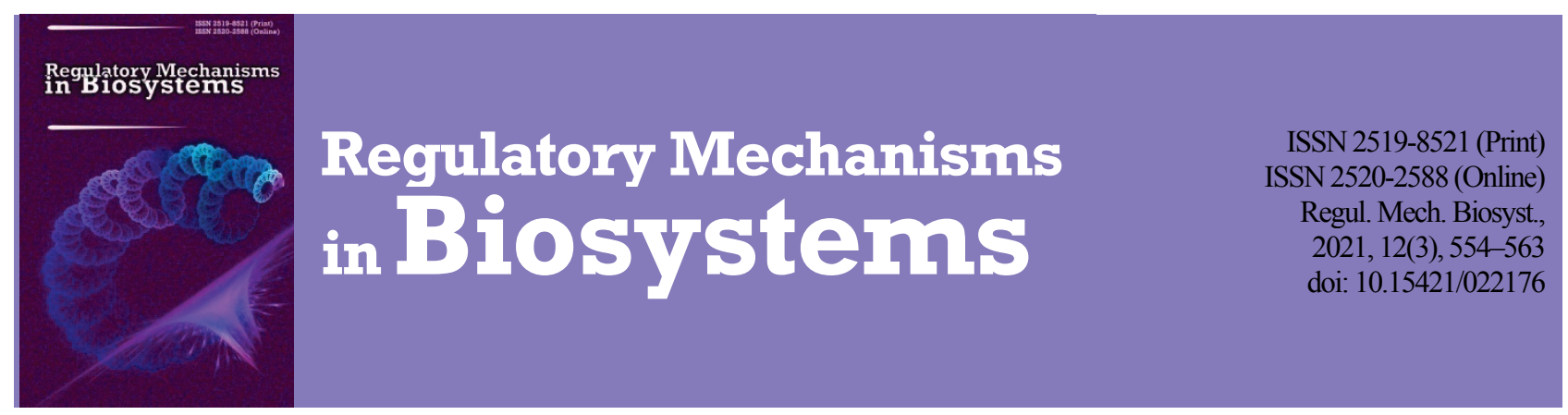

\title{
Effect of Salvia officinalis and $S$. sclarea on rats with a high-fat hypercaloric diet
}

\author{
M. A. Lieshchova*, A. A. Bohomaz*, V. V. Brygadyrenko**** \\ *Dnipro State Agrarian and Economic University, Dnipro, Ukraine \\ **Oles Honchar Dnipro National University, Dnipro, Ukraine
}

Article info

Received 17.07.2021

Received in revised form 11.08.2021

Accepted 12.08.2021

Dipro State Agrarian and Economic University, Serhii Efremov st., 25 , Dnipro, 49600, Ukraine Tel.: + 38-067-256-24-86. E-mail:

lieshchova.m.o@dsau.dp.ua

Oles Honchar Dnipro National University,

Gagarin av., 72,

Dnipro, 49010, Ukraine.

Tel.: +38-050-93-90-788.

E-mail:brigad@ua.fm

\author{
Lieshchova, M. A., Bohomaz, A. A., \& Brygadyrenko, V. V. (2021). Effect of Salvia officinalis and S. sclarea on rats with a high-fat \\ hypercaloric diet. Regulatory Mechanisms in Biosystems, 12(3), 554-563. doi:10.15421/022176
}

Phytotherapy for the correction of excess body weight is widely used. However, a comprehensive study of herbal preparations on the organism of model animals has been carried out only for a few plant species. Supplementing the diet of rats with closely related sage species (Salvia officinalis L. and S. sclarea L.) against the background of high-fat hypercaloric diet triggered multidirectional changes in their metabolism. The addition of crushed dry shoots of $S$. officinalis to the diet of animals led to a sharp increase in their body weight (up to $130.8 \%$ of the initial one in 30 days of the experiment). The body weight of the rats treated with $S$. sclarea for 30 days increased only up to $103.8 \%$ of their initial weight and was lower than in the control group. Addition of S. officinalis caused an increase in daily weight gain up to $253.1 \%$ of the control group, and S. sclarea - its decrease to $27.8 \%$ of the daily weight gain in the control group. In the S. officinalis group, the relative weight of the brain, spleen, and thymus decreased, while in the $S$. sclarea group, the relative weight of the thymus decreased and that of the colon increased. Under the influence of S. officinalis, the concentration of urea, total bilirubin, and triglycerides in the blood plasma of male rats decreased and the concentration of total protein and the activity of alkaline phosphatase increased. While consuming S. sclarea shoots, there was an increase of alkaline phosphatase activity in the rats' blood, but atherogenic index ( $23.1 \%$ of the level of the control group) sharply dropped due to an increase in the concentration of high-density lipoprotein cholesterol ( $286.9 \%$ of the control) and a decrease in the concentration of low-density lipoprotein cholesterol (67.7\% of control). In rats feeding on $S$. sclarea shoots, we observed a decrease in the concentration of triglycerides in the blood (39.9\% of the control), a decrease in the activity of gammaglutamyl transferase $(62.8 \%)$, and an increase in the $\mathrm{Ca} / \mathrm{P}$ ratio $(132.5 \%$ of the control group). No significant changes were observed in $\mathrm{CBC}$ and WBC differential of male rats when eating S. officinalis and S. sclarea shoots. According to the results of the open field test, the physical and orientational activity of male rats under the influence of $S$. officinalis significantly decreased by the end of the experiment. Emotional status of rats, on the contrary, decreased when they ate dry crushed shoots of $S$. sclarea in the composition of the food. Thus, excess body weight of rats in the conditions of hypercaloric diet led to more pronounced deviations from the norm while consuming dry crushed shoots of $S$. officinalis. The addition of $S$. sclarea dry crushed shoots to the animals' diet normalized the body weight in comparison with the control group, reduced the negative manifestations of obesity at the biochemical and organismal levels. In this regard, the substances that contains $S$. sclarea should be carefully studied for anti-atherosclerotic activity, and tea supplemented with $S$. sclarea shoots can be recommended as a corrective supplement in the diet of overweight people.

Keywords: relative mass of the organs; increase in the body weight; high-fat diet; garden sage; clary sage; phytotherapy; obesity correction.

\section{Introduction}

Aromatic plant species of the genus Salvia are important medicinal herbs that are highly recommended because of their therapeutic properties: antiseptic, antispasmodic, antimicrobial, antirheumatic, antidiabetic and flatus-relieving (Pop et al., 2016; Jakovljević et al., 2019; Ghowsi et al., 2020). Species of the Salvia genus have significant antioxidant and antiproliferative properties against tumour cells (Loizzo et al., 2014). Sage antioxidant features are explained by a high level of phenolic compounds (Hudz et al., 2019).

Abietane diterpenoids (ADs) - compounds synthesized from the roots of various species of Salvia - contain aethiopinone, 1-oxoaethiopinone, salvipisone, and ferruginol, which displayed promising cytotoxic activity toward several lines of human tumour cells, e.g., the breast adenocarcinoma MCF7, HeLa, epithelial carcinoma, prostate adenocarcinoma PC3, and human melanoma A375 (Vaccaro et al., 2020). Aethiopinone, an onaphto-quinone diterpene, produced from the roots of various Salvia plants, exerted selective cytotoxicity against the A375 melanoma cell line (Vaccaro et al., 2019). Such compounds as ferruginol, salvipisone, and carnosic acid also showed antiproliferative activity (Vaccaro et al., 2019). The antioxidant activity of these extracts was evaluated in vitro using
DPPH (alpha, alpha-diphenyl-beta-picrylhydrazyl), FRAP (ferric reducing antioxidant power) and HAPX (haemoglobin / ascorbate peroxidase activity inhibition) methods (Hanganu et al., 2019). The polyphenolic profile of some Salvia species (S. aetiopsis, S. austriaca, S. sclarea, S. nutans, $S$. verticilatta and $S$. nemorosa) was found to have some common elements (caffeic acid, p-cumaric acid, isoquercitrin, hyperoside, luteolin, apigenin) and other rare compounds (chlorogenic acid, caftaric acid, ferulic acid, quercitrin, rutin, quercetin, kaempferol). All studied species of the Salvia genus were confirmed to contain significant amounts of polyphenolic compounds (22.25-118.75 mg GAE/g dry weight material plant) and could be used as a valuable resource of natural antioxidants together with S. officinalis, the most known one (Francik et al., 2020).

It was found that extracts from collected plants were effective antioxidants in three different in vitro assays (DPPH, ABTS, FRAP and superoxide anion scavenging activity) (Vergine et al., 2019). Therefore, they can be used as natural ingredients in herbal medicines, functional foods, or as bioactive molecules sources.

Common sage (S. officinalis L.) is a well-known medicinal plant that is cultivated in several European countries. In sage, leaves or flowering tops are used as raw materials. The value of sage as a medicinal herb lies in its essential oil, which contains D- $\alpha$-pinene, cineole (about 15\%), $\alpha$ - and 
$\beta$-thujone, D-borneol and D-camphor. The leaves also contain alkaloids, flavonoids, tannins, oleanolic and ursolic acids, and the fruits contain 19$25 \%$ fatty oil, represented mainly by linoleic acid glycerides. Having confirmed antioxidant properties, $S$. officinalis was used as a reference plant (Miliauskas et al., 2004). Free radical bounding capacities of extracts and their total content of phenolic compound were observed to correlate.

Clary sage (S. sclarea L.) is an equally important medicinal herb of this genus. It is a widespread field crop used for essential oil production (Cui et al., 2015; El-Gohary et al., 2020; Grigoriadou et al., 2020; Tuttolomondo et al., 2020). Essential oil of clary sage is isolated from the flowers and leaves. The plant is cultivated in Moldova, Russia, Bulgaria, France, Germany and other countries. Currently, there are micropropagation techniques to industrially produce clonally stable clary sage plants that would be used for commercial purposes (Erisen et al., 2020).

The essential oils of $S$. sclarea have been known since Ancient Greece (Pitarokili et al., 2002). Sixty six compounds have been identified, which is $93.3-98.2 \%$ of oils, their main compounds are linalyl acetate (19.8-31.1\%), linalool (18.5-30.4\%), geranyl acetate (4.5-12.1\%), and a-terpineol (5.1-7.6\%). There are two types of aromatic products - sage concrete and sage absolute. The essential oil of varies in composition depending on the sage's growing conditions and is determined by a wide variety of environmental factors (Dogan, 2020). It was found that the rate of essential oil in the plant grown without boron was $0.11 \%$, while in the plant grown with pure boron it was $0.44 \%$ (Karayel, 2020). Therefore, pure boron has a positive effect on the ratio of essential oil and components of clary sage.

The volatile oil compounds of $S$. sclarea and $S$. officinalis were identified to be relatively richer in terpenes but the amount of volatile oil depended on ecological factors (Karayel \& Akcura, 2019).

While seed oil of $S$. officinalis could be categorized as oleic-linoleic oil, the fatty acid prevailing in S. sclarea was linolenic acid (around 54\%). In both seeds and oils, main isomers among tocols were $\gamma$-tocopherol and $\alpha$-tocopherol. The concentration of carotenoids accounted for about $0.75 \mathrm{mg} / 100 \mathrm{~g}$ of seeds and $0.16 \mathrm{mg} / 100 \mathrm{~g}$ of oils, lutein being prevailent. Antioxidant potential exerted by oil from $S$. officinalis and its seeds was greater than such of investigated samples of $S$. sclarea, possibly because of larger amounts of overall vitamin $E$ and carotenoids (Zivkovic et al., 2017).

Effects of essential oil from S. sclarea on pulse, blood pressure and mood were analyzed on healthy female and male humans (Mitic et al., 2020). The pulse rate decreased more significantly in women than in men. In general, these effects may depend on the method of application (inhalation or dermal application) and sex. Clinical studies confirmed that oil from $S$. sclarea is effective in reducing stress, depression and as analgesic agents in primary dysmenorrhea (Mahboubi, 2020). Studies have confirmed that clary sage has antioxidant, antimicrobial, cytotoxic and antiinflammatory effects.

By applying $S$. sclarea topically as part of aromatherapy, the severity of menstrual cramps was effectively reduced (Han et al., 2006). Therefore, women who experience menstrual cramps or dysmenorrhea may be offered aromatherapy as part of their nursing care (Han et al., 2006). In aromatherapy, oil from clary sage is used for women during their menstrual cycle, childbirth and menopause (Mahboubi, 2020).

Essential oil from $S$. sclarea damages the cell membrane and changes its permeability, thereby leading to the release of macromolecular substances of cytoplasm such as ATP and DNA. The antimicrobial effect of essential oil from $S$. sclarea is a result of a series of events occurring on the cell surface and within the cytoplasm (Cui et al., 2015).

Abietane diterpenoids isolated from culture of $S$. sclarea transformed roots inhibited pathogenic microorganisms as Acanthamoeba spp. (Kuzma et al., 2015). Microorganisms of the Acanthamoeba genus are well known pathogens of different diseases like granulomatous amoebic encephalitis (GAE), chronic progressive disease of the central nervous system, amoebic keratitis (AK), chronic eye infection, amoebic pneumonitis (AP), chronic lung and skin infections. The activity of Acanthamoeba was notably inhibited by ferruginol. This component produced $72 \%$ growth inhibition of Acanthamoeba in a 3-day exposure period $\left(\mathrm{IC}_{50} 17.45 \mu \mathrm{M}\right)$, whereas such activity of aethiopinone and 1-oxo-aethiopinone was only at the level of 55-56\% (Kuzma et al., 2015). Essential oil S. sclarea was observed to have notable antifungal activity (Fraternale et al., 2005). 2,3-Dehyd- rosalvipisone, sclareol, manool, 7-oxoroyleanone, spathulenol and caryophyllene oxide were active against Staphylococcus aureus, the first and third components exerted significant action toward Candida albicans, while the last compound was active against Proteus mirabilis (Ulubelen et al., 1994). Lately, the antimicrobial and fungicidal effects of S. sclarea essential oil has found application in other areas of life. Results of the recent studies showed high fungicidal efficacy of $S$. sclarea for the packaging materials (Kostova et al., 2020). During the investigated shelf life period, inhibition of Candida albicans accounted for around $100 \%$. Suppression of $C$. albicans during the investigated shelf life of the package accounted for $100 \%$. Recycled paper showed a high efficiency against Aspergillus brasiliensis (81.9-99.2\%). Bactericidal effect of the studied packaging materials processed with sage oils was higher against Escherichia coli and lower against Gram-negative bacterium Salmonella abony (Kostova et al., 2020). Therefore, clary sage essential oil could be used as an antimicrobial agent in the food industry because of its good antimicrobial features so as to improve products' quality and extend their shelf life.

After the essential oil is obtained from the raw material of clary sage, sclareol is isolated from the green parts of the plant - diterpene alcohol, a representative of terpenoids. Methanol was experimentally selected as the optimal solvent for ultrasound-assisted extraction of phenolic compounds from these plants (Jasicka-Misiak et al., 2018). In glandular trichomes of S. sclarea, bicyclic diterpene (-)-sclareol is accumulated (Schmiderer et al., 2008). In the flavours and fragrances industry, it is also used as the raw material for synthesis of Ambrox, a synthetic analogue of ambergris (Gunnewich et al., 2013).

Acetone extract of $S$. sclarea contains nine diterpenes: sclareol, manool, salvipisone, ferruginol, microstegiol, candidissiol and 7-oxoroyleanone, 2,3-dehydrosalvipisone and 7-oxoferruginol-18-al. Furthermore, the plant was found to contain two sesquiterpenes, caryophyllene oxide, spathulenol, alpha-amyrin, beta-sitosterol and the flavonoids apigenin, luteolin, 4'-methylapigenin, 6-hydroxyluteolin-6,7,3',4'tetramethyl ether, 6-hydroxyapigenin-7,4'-dimethyl ether (Ulubelen et al., 1994).

The methanol extracts of $S$. sclarea inhibited the growth of all tested bacterial strains, also this plant had a prominent antioxidant activity (Firuzi et al., 2013). Sclareol caused inhibition of prostaglandin (PG) F-2 alpha-, oxytocin-, acetylcholine-, carbachol-, KCl-, and Bay K 8644-induced uterine contraction and led to an analgesic effect in the writhing test (Wong et al., 2020). Sclareol takes effect on $\mathrm{Ca}^{2+}$ level and mediates oxytocin receptor (OXTR), myosin light chain kinase (MLCK), extracellular signal-regulated kinase, p-p38, cyclooxygenase-2 (COX-2), and phosphomyosin light chain 20 (p-MLC20) protein expression. Summarizing these results, sclareol is a promising alternative supplement in treatment of dysmenorrhea (Wong et al., 2020).

The strongest antioxidant capacity among 5 studied species of Salvia was exhibited by extract from $S$. officinalis (Pop et al., 2016). Extracts from $S$. sclarea and $S$. officinalis displayed antibacterial activity toward Bacillus cereus, Staphylococcus aureus and Pseudomonas aeruginosa. Nonetheless, research has revealed resistance of Salmonella typhimurium to extract of S. sclarea and resistance of Escherichia coli to the extract of S. officinalis (Pop et al., 2016; Zazharskyi et al., 2019).

Intraperitoneally injected sclareol was studied for its effects that reduce the tumour volume and shift the cytokine profile. Also, there has been an investigation of whether injection of sclareol intraperitoneally can improve the outcome of cancer therapy by suppressing the regulatory Tcells (Noori et al., 2013). The results demonstrated significant decrease in tumour size. Moreover, in the group that was intraperitoneally injected with sclareol, the level of IL-4 significantly dropped and the level of IFNgamma increased. An assay of cell proliferation also revealed that the splenocytes of the experimental animals significantly increased. Noori et al. (2013) proposed that sclareol can enhance cancer therapy as an immunostimulator by reducing regulatory T-cells $\left(\mathrm{T}_{\mathrm{regs}}\right)$ frequency and size of tumour. Sclareol also demonstrated immuno-therapeutic efficacy after direct intra-tumoral injection.

According to Fiore et al. (2006), there was potential antitumoral activity of $S$. sclarea extracts, determined by MTT test, on nine human cancer cell lines: glioblastoma (DBTRG-05MG, T98G, U-87MG), colorectal adenocarcinoma (WiDr and HT-29), prostate adenocarcinoma (MDA Pca2b), choriocarcinoma (JEG-3), endometrium adenocarcinoma (HEC-1A) and 
B lymphoblast (CIR). Extracts of $S$. sclarea also demonstrated cytotoxic activity to various degrees depending on the type of cell line (Fiore et al., 2006). The results confirmed that Salvia may be considered as a natural source of potential antitumor agents (AlMotwaa et al., 2020).

There were four diterpenoids isolated from transformed roots of S. sclarea, namely ferruginol, salvipisone, aethiopinone and 1-oxoaethiopinone (Rozalski et al., 2006). Determining caspase-3 activity showed that salvipisone and aethiopinone could induce apoptosis in time- and concentration-dependent ways. Thus, aethiopinone and salvipisone diterpenoids from $S$. sclarea could be useful in treating human cancers, specifically in the drug-resistant cases (Rozalski et al., 2006).

The lectin isolated from seeds of $S$. sclarea (SSL) recognizes the Tnantigen (GalNAc alpha $1->$ Ser/Thr), which is expressed in some human carcinomas (Wu, 2005). This was confirmed by Medeiros et al. (2000), whose studies found that SSL from $S$. sclarea seeds recognized the Tnantigen (GalNAc alpha-O-Ser/Thr), a specific marker of many human carcinomas. SSL is an acidic (pI 5.5), 60-61 kDa dimeric glycoprotein that is composed of identical subunits, interlinked by a single disulfide bond.

Specificity of lectin from S. bogotensis seeds and its high affinity for the Tn-antigen, commonly found in tumour cells, is making this protein a useful element for immunohistochemical and cellular studies (Vega \& Perez, 2006).

The antiviral effect of sclareol also has a significant potential. It is well known that filoviruses can trigger severe hemorrhagic fever in humans. So far, the most contagious filovirus is Ebola virus (EBOV). Sclareol and sclareolide exerted inhibitory activity toward all tested filoviruses, indicating their broad range of activities against filoviruses (Chen et al., 2020).

Inhibitory effect of sclareol was investigated on osteoclastogenesis and progression of postmenopausal osteoporosis (Jin et al., 2019). Sclareol was seen to have a protective effect against bone loss in the conditions of ovariectomy-induced mouse model. Jin et al. (2019) results suggested that sclareol is a potentially valueable therapeutic agent during postmenopausal osteoporosis.

Traditionally, $S$. sclarea is used as an agent against gingivitis, stomatitis and aphthae (Kosti et al., 2017). Treatment with $S$. sclarea extract significantly lowered the inflammation process by decreasing the levels of IL-1 beta, IL- 6 and TNF-alpha, reducing lesions in the gingival tissue and preserving alveolar resorption of the bone, compared with the untreated group of the rats (Kosti et al., 2017). Extract from S. sclarea showed an anti-inflammatory effect in periodontitis induced by E. coli lipopolysaccharide, suggesting that it could be used as a therapeutic agent in treating periodontal diseases. There was increase in the inhibition depending on time of contact. Essential oils from $S$. sclarea can demonstrate better results when used in bioadhesive formulations that would take peripheral analgesic and anti-inflammatory actions on a local level (Peana et al., 1999).

Diffusion of essential oil of S. sclarea and its infiltration through porcine buccal mucosa was has been considered useful in stomatology. Compared to the other compounds, the ones having terpenic structure penetrated through the porcine buccal mucosa best (Ceschel et al., 1998).

Strongyloides papillosus (Wedl, 1856) is a common nematode of ruminants, and 24 hour-influence of S. sclarea at different doses had significant effects on the survival of invasive and noninvasive types of larvae (Boyko \& Brygadyrenko, 2016). Aqueous extracts of S. sclarea inflorescences killed $50 \%$ of $S$. papillosus invasive larvae in $464+/-192 \mathrm{mg} / \mathrm{L}$ concentration and non-invasive larvae in $327 \pm 186 \mathrm{mg} / \mathrm{L}$ concentration (Palchykov et al., 2019).

Saivia sclarea is a rich source of terpenoid compounds and may be used as a bio-based pesticide in nature (Bozok \& Ulukanli, 2016). In the phytotoxicity assay, essential oil from $S$. sclarea showed significant dose dependent potential toxicity on Lactuca sativa L., Lepidium sativum L. and Portulaca oleracea L. (Bozok \& Ulukanli, 2016).

Therefore, the objective of the study was the effect of the herbs on the organism of laboratory rats on a high-fat diet during a 30-day experiment.

\section{Materials and methods}

The choice of animals for the experiment, research protocols, withdrawal of animals from the experiment were approved by the local ethical committee of the Dnipro State Agrarian and Economic University. The maintenance, nutrition, care for animals and their withdrawal from the experiment were carried out in compliance with the principles described in the "European Convention for the Protection of Vertebrate Animals used for Experiments and for Other Scientific Purposes" (Strasbourg, March 18, 1986, ETS No. 123) and in the order No. 3447-IV from February 21, 2006 "About protection of animals from cruel treatment" (Ukraine).

A control group and two experimental groups of 8 animals in each were formed from 24 adult white outbred male laboratory rats weighing $200 \pm 10 \mathrm{~g}$. The rats were housed in polycarbonate cages with steel lattice lids and a stern recess, 4 rats per cage. Rats were kept in a room with a temperature of $20-22{ }^{\circ} \mathrm{C}$ and a relative humidity of $50-65 \%$. The light regime was 12 hours of light and 12 hours of darkness. Ventilation was carried out according to the regime. The animals received water ad libitum. The duration of the experiment was 30 days.

The control group of animals was fed a high-fat diet (3600 kcal $/ \mathrm{kg})$, which was based on the standard diet (75\% grain mixture (corn, sunflower seeds, wheat, barley, soybeans), $8 \%$ roots (potatoes, carrots), $2 \%$ meat and bone flour, $2 \%$ mineral-vitamin complex) with the addition of $15 \%$ sunflower oil. Animals in the experimental groups received semi-synthetic high-fat diets supplemented with $5 \%$ of medicinal plants. To the diet of the first experimental group,we added 5\% of dry shredded shoots of S. officinalis, and the second experimental group was given 5\% of dry shredded $S$. sclarea shoots. Herbal raw material was collected manually, dried without access to direct sunlight in the room temperature. The main ingredients of the diet were ground in a mill (grain, meat and bone meal, mineral-vitamin complex, dry shoots of medicinal plants) and mixed, then sunflower oil was added and granules were made at the rate of $4.200 \mathrm{~g}$ for each group for the entire experiment period (30 days). Fresh root crops were additionally given in an appropriate amount every day. The animals had free access to the food. During the experiment, we monitored the amount of food consumed by each group per day and the total amount for the entire period of the experiment.

Morphometric parameters (body weight, abdominal circumference) were determined on the first day and the 30th day of the experiment. The total increase in animal weight and the daily increase in live body weight were calculated (Bilan et al., 2019; Brygadyrenko et al., 2019; Lieshchova et al., 2018, 2019, 2020). The locomotor activity and the emotional status in the experimental rats were studied in the open field test. We used an installation consisting of a square area of $1 \mathrm{~m}^{2}$, divided into 16 squares and bounded by an opaque wall $20 \mathrm{~cm}$ high. The experiment was carried out in complete silence with intense illumination of the field itself. An experimental rat, was taken from a cage in a previously darkened room, and was placed in the center of the field. The exposure time was 2 minutes. The animals were tested for four days (1-4 days) at the beginning of the experiment and four days at the end (26-30 days). The number of squares that rats crossed was counted: peripheral and central ones - motor activity was assessed; peripheral (with support on the wall) and central (without support on the wall) standings upright squares orientational activity; the number of acts of grooming, defecation and urination - emotional status (Lieshchova et al., 2021).

The animals were euthanized on the 30 th day of the experiment under anaesthesia ( $80 \mathrm{mg} / \mathrm{kg}$ ketamine and $12 \mathrm{mg} / \mathrm{kg}$ xylazine, intraperitoneally) by blood withdrawal with cardiac puncture. After autopsy, the state of the internal organs was visually assessed for the presence of pathological changes. The sampling of organs and tissues (heart, liver, lungs, thymus, spleen, stomach, small and large intestines, kidneys, brain) was performed with surgical instruments and they were weighed. The mass of internal organs was determined with the accuracy of $0.01 \mathrm{~g}$.

Blood samples that we collected during euthanasia were subjected to biochemical and morphological studies. Biochemical parameters were determined using an automatic analyzer Miura 200 (I.S.E. Srl, Italy) and with High Technology reagent kits (USA), PZ Cormay S.A. (Poland) and Spinreact S.A. (Spain). The erythrocytes and white blood cells (WBC) count in the rats' stabilized blood was determined using an automatic hematological analyzer BC-2800Vet and Mindray (Lieshchova et al., 2018, 2019, 2020; Brygadyrenko et al., 2019). For the white blood cell differential, blood smears were prepared by Pappenheim method with their further staining according to Romanowsky-Giemsa. The total protein was deter- 
mined using the biuret method; globulins and protein coefficient - calculated; albumin - by reaction with bromcresol green; the activity of aspartate aminotransferase (AST) and alanine aminotransferase (ALT) - kinetic, based on the optical Warburg test; alkaline phosphatase - enzymatic with n-nitrophenyl phosphate; glucose - by glucose oxidase method; urea enzymatic, kinetic using urease and glutamate dehydrogenase; creatinine by the modified Jaffe method without deproteinization; total bilirubin - by a method based on oxidation in the presence of vanadate as an oxidizing agent; total calcium - by colorimetric method with Arsenazo III, inorganic phosphorus - by direct phosphomolybdate method without deproteinization, gamma-glutamyl transferase - kinetic method with L-gamma-glutamyl-3-carboxy-4-nitroanilide. The concentration of total cholesterol was determined using the colorimetric, enzymatic method with esterase and cholesterol oxidase; triglycerides - by colorimetric, enzymatic methods with glycerophosphoric oxidase; HDL and LDL - by direct enzymatic method, the atherogenic index were calculated. From biochemical markers of inflammation, C-reactive protein was determined by the method of highly sensitive latex-enhanced immunoturbidimetry.

All the data were analysed using Statistica 8.0 software (StatSoft Inc., USA). Results in the tables are demonstrated as $\mathrm{x} \pm \mathrm{SD}$ (mean \pm standard deviation). Differences between the control and experimental groups values were determined using the Tukey test (with consideration of Boniferroni's correction), where the differences were considered significant at $\mathrm{P}<0.05$.

\section{Results}

The addition of S. officinalis dry shoots to the male rats' diet notably increased the body weight of the animals compared with the control group: the body weight in the control group increased to $111.5 \%$ of the initial, and in the S. officinalis group - up to $130.8 \%$ in 30 days of the experiment (Fig. 1a). The body weight of rats that had consumed diet supplemented with dry crushed shoots of S. sclarea was only $103.8 \%$ of their initial weight (Fig. 1b), that is, it was significantly lower than in the control group.

Rats that consumed dry crushed shoots of $S$. officinalis were observed to have insignificantly (at the tendency level, $\mathrm{P}>0.05$ ) reduced food intake to $85.3 \%$ of the control group level (Table 1). Animals that were fed on diet supplemented with $S$. sclarea shoots did not change feed intake, but increased water intake at the level of the trend to $116.9 \%$ of the level of the control group. With a change in the daily body weight gain in animals, there were multidirectional changes as compared with the control group (Table 1): S. officinalis caused an increase in weight gain up to $1771 \mu \mathrm{g} /$ day $(253.1 \%$ of the control group), and $S$. sclarea - a decrease in body weight gain to $194 \mu \mathrm{g} /$ day ( $27.8 \%$ of the control group). Moreover, such abrupt changes in body weight in animals did not affect the abdominal circumference, which did not differ from the control group.
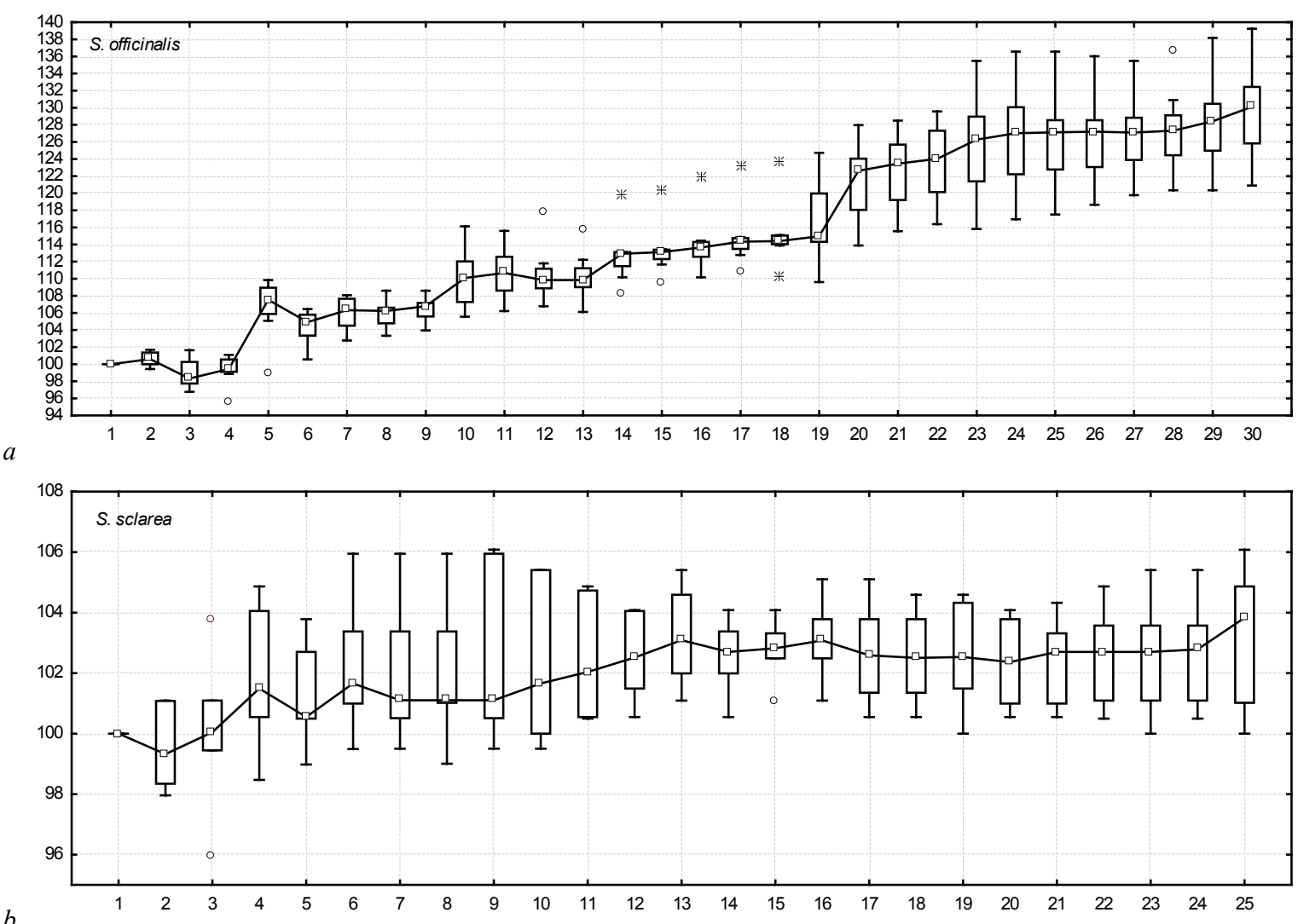

Fig. 1. Change in the rats' body weight when chopped shoots of Salvia officinalis L. ( $a$ ) and S. sclarea L. (b) were added to their diet: the abscissa is the day of the experiment, the ordinate is the body weight of the animals (\% relative to the initial body weight before the start of the experiment, taken as $100 \%$ for each of the experimental animals); small square - median, upper and lower borders of the rectangle $-25 \%$ and $75 \%$ quartiles, vertical line - minimum and maximum values, circles - outliers; $n=8$

Table 1

Change in the body weight and food consumption of young male rats under the influence of Salvia officinalis $\mathrm{L}$. and $S$. sclarea $\mathrm{L}$. addition to their $\operatorname{diet}(\mathrm{x} \pm \mathrm{SD}, \mathrm{n}=8$, duration of experiment 30 days)

\begin{tabular}{|c|c|c|c|c|c|}
\hline Parameter & Control & S. officinalis & S. officinalis compared to the control, $\%$ & S. sclarea & S. sclarea compared to the control, $\%$ \\
\hline Food consumption by rats, $\mathrm{g} /$ day & 20.09 & 17.14 & 85.3 & 19.97 & 99.4 \\
\hline Water consumption by rats, g/day & 18.42 & 17.21 & 98.9 & 21.53 & 116.9 \\
\hline Body weight change, $\mu \mathrm{g} /$ day & $700 \pm 271$ & $1771 \pm 373^{* * *}$ & 253.1 & $194 \pm 127^{* * *}$ & 27.8 \\
\hline Body weight change, $\% /$ day & $13.6 \pm 5.9$ & $29.3 \pm 5.8 * * *$ & 215.0 & $3.3 \pm 2.1 * * *$ & 24.3 \\
\hline Abdominal circumference, $\mathrm{cm}$ & $14.00 \pm 0.46$ & $13.79 \pm 0.79$ & 98.5 & $13.83 \pm 1.11$ & 98.8 \\
\hline
\end{tabular}

Note: different letters indicate values that differed one from another reliably within one line of the table according to the results of comparison using the Tukey test with Bonferroni correction. 
The overall increase in the body weight in the group consuming $S$. officinalis led (Table 2) to a significant decrease in the relative weight of the brain (to $77.7 \%$ compared with the control group), spleen (to $80.4 \%$ ) and thymus (to $59.1 \%$ ). After consumption of S. sclarea, the relative weight of the thymus in male rats also reduced (to $43.4 \%$ of the control), but, at the same time, there was a significant increase in ther relative weight of the colon (up to $159.7 \%$ compared with the control group, Table 2). No other significant changes in the relative mass of the organs in animals from experimental groups were recorded.

Change in blood biochemical parameters of male rats fed on S. officinalis manifested itself in a decrease of the urea concentration (78.3\% of control), total bilirubin (up to 59.5\%), triglycerides (up to 67.1\%), a moderate increase of the total protein in blood plasma (up to $109.8 \%$ ) and a drastic increase in alkaline phosphatase activity (up to $435.1 \%$ of control, Table 3). There were no significant changes compared to the control group in other biochemical blood parameters that we studied in the $S$. officinalis group.

Consuming S. sclarea shoots in the composition of feed by rats also caused an increase in the alkaline phosphatase activity in blood plasma (however, weaker than in the previous group - only up to $276.5 \%$ of control, Table 3). More prominent changes in the group of animals eating S. sclarea were observed in fat metabolism: the index of atherogenicity decreased sharply - to $23.1 \%$ of the control group level (Table 3). This was due to a sharp increase in the concentration of high density lipoprotein cholesterol (up to $286.9 \%$ of the level of the control group) and an insigni- ficant (at the tendency level, $\mathrm{P}>0.05$ ) decrease in the concentration of low density lipoprotein cholesterol (up to $67.7 \%$ of the level of the control group). Also, in the group of rats that were feeding on S. sclarea, an increase in the concentration of cholesterol (up to $128.5 \%$ of the control group) and a strong decrease in the concentration of triglycerides (up to $39.9 \%$ of the control, more pronounced than in the group of $S$. officinalis) were recorded. In addition, there was a decrease in gamma-glutamyl transferase activity in the blood of animals that consumed $S$. sclarea (up to $62.8 \%$ of the control group) and an increase in the $\mathrm{Ca} / \mathrm{P}$ ratio (up to $132.5 \%$ of the control group). Other investigated blood biochemical parameters in the group of animals that consumed $S$. sclarea did not show significant differences (Table 3).

Under the influence of the $S$. officinalis and $S$. sclarea chopped shoots added to the diet of rats, there were no significant changes in complete blood count (CBC) and white blood cell (WBC) differential of male rats (Table 4)

Physical activity (Fig. 2a) in male rats fed $S$. officinalis significantly decreased by the end of the experiment; the addition of $S$. sclarea to the diet of animals caused an insignificant decrease (at the tendency level, P > 0.05 ) in the physical activity of rats. The effect of $S$. officinalis also significantly decreased the orientational activity in animals (Fig. 2b). On the other hand, the emotional status (Fig. 2c) of rats on the diet with S. officinalis did not significantly change, while eating dry crushed shoots of $S$. sclarea as part of the compound feed significantly reduced the emotional status of experimental animals.

\section{Table 2}

Change in organs' relative mass (\%) of male rats under the influence of Salvia officinalis L. and S. sclarea L. supplementation to their $\operatorname{diet}(\mathrm{x} \pm \mathrm{SD}, \mathrm{n}=8$, duration of experiment 30 days)

\begin{tabular}{|c|c|c|c|c|c|}
\hline Organ & Control & S. officinalis & S. officinalis compared to the control, $\%$ & S. sclarea & S. sclarea compared to the control, $\%$ \\
\hline Heart & $0.352 \pm 0.023$ & $0.350 \pm 0.026$ & 99.6 & $0.375 \pm 0.027$ & 106.6 \\
\hline Liver & $4.08 \pm 0.17$ & $4.04 \pm 0.31$ & 99.1 & $4.25 \pm 0.28$ & 104.2 \\
\hline Lungs & $0.979 \pm 0.169$ & $0.836 \pm 0.128$ & 85.4 & $1.056 \pm 0.114$ & 108.0 \\
\hline Thymus & $0.285 \pm 0.046$ & $0.168 \pm 0.038^{* * *}$ & 59.1 & $0.124 \pm 0.101^{* *}$ & 43.4 \\
\hline Spleen & $0.370 \pm 0.036$ & $0.298 \pm 0.037 *$ & 80.4 & $0.382 \pm 0.067$ & 103.3 \\
\hline Stomach & $0.699 \pm 0.060$ & $0.786 \pm 0.165$ & 112.4 & $0.955 \pm 0.335$ & 136.6 \\
\hline Small intestine & $2.58 \pm 0.52$ & $2.38 \pm 0.52$ & 92.1 & $2.21 \pm 0.36$ & 85.7 \\
\hline Caecum & $0.509 \pm 0.176$ & $0.457 \pm 0.068$ & 89.8 & $0.487 \pm 0.117$ & 95.7 \\
\hline Colon & $0.374 \pm 0.085$ & $0.430 \pm 0.205$ & 115.1 & $0.596 \pm 0.082^{* * *}$ & 159.7 \\
\hline Rectum & $0.398 \pm 0.073$ & $0.276 \pm 0.068$ & 69.2 & $0.359 \pm 0.095$ & 90.2 \\
\hline Right kidney & $0.358 \pm 0.031$ & $0.394 \pm 0.177$ & 110.1 & $0.345 \pm 0.045$ & 96.3 \\
\hline Left kidney & $0.372 \pm 0.040$ & $0.381 \pm 0.167$ & 102.4 & $0.336 \pm 0.039$ & 90.4 \\
\hline Brain & $0.867 \pm 0.052$ & $0.673 \pm 0.079 * * *$ & 77.7 & $0.901 \pm 0.096$ & 104.0 \\
\hline
\end{tabular}

Note: see Table 1.

Table 3

Change in blood biochemical parameters of male rats under the influence of S. officinalis L. and S. sclarea $\mathrm{L}$. ( $\pm \mathrm{SD}, \mathrm{n}=8$, duration of experiment 30 days)

\begin{tabular}{|c|c|c|c|c|c|}
\hline Parameters & Control & S. officinalis & $\begin{array}{l}\text { S. officinalis compared } \\
\text { to the control, } \%\end{array}$ & S. sclarea & $\begin{array}{l}\text { S. sclarea compared } \\
\text { to the control, } \%\end{array}$ \\
\hline Total protein, $\mathrm{g} / \mathrm{L}$ & $77.0 \pm 4.9$ & $84.6 \pm 1.8^{*}$ & 109.8 & $82.7 \pm 4.9$ & 107.4 \\
\hline Albumins, $\mathrm{g} / \mathrm{L}$ & $39.6 \pm 2.6$ & $43.0 \pm 1.1$ & 108.7 & $42.0 \pm 2.0$ & 106.1 \\
\hline Globulins, $\mathrm{g} / \mathrm{L}$ & $37.4 \pm 3.9$ & $41.6 \pm 1.3$ & 111.1 & $40.7 \pm 3.2$ & 108.7 \\
\hline Protein coefficient, $\mathrm{U}$ & $1.100 \pm 0.151$ & $1.029 \pm 0.045$ & 93.5 & $1.050 \pm 0.050$ & 95.5 \\
\hline Urea, $\mathrm{mmol} / \mathrm{L}$ & $6.8 \pm 1.0$ & $5.4 \pm 0.6^{*}$ & 78.3 & $6.1 \pm 1.1$ & 88.9 \\
\hline Blood urea nitrogen $(\mathrm{BUN}), \mathrm{mg} / 100 \mathrm{~g}$ & $13.1 \pm 2.0$ & $10.2 \pm 1.1$ & 78.3 & $11.6 \pm 2.1$ & 89.1 \\
\hline Creatinine, $\mu \mathrm{mol} / \mathrm{L}$ & $63.0 \pm 4.4$ & $67.1 \pm 5.8$ & 106.6 & $65.8 \pm 9.6$ & 104.5 \\
\hline Aspartate aminotransferase (AST), U/L & $186 \pm 61$ & $187 \pm 38$ & 100.5 & $210 \pm 25$ & 112.9 \\
\hline Alanine aminotransferase (ALT), U/L & $131 \pm 41$ & $123 \pm 21$ & 94.0 & $109 \pm 28$ & 83.6 \\
\hline De Ritis ratio (AST/ALT), U & $1.63 \pm 0.78$ & $1.51 \pm 0.19$ & 93.0 & $2.05 \pm 0.59$ & 125.9 \\
\hline Alkaline phosphatase, $\mathrm{U} / \mathrm{L}$ & $129 \pm 64$ & $561 \pm 243 * * *$ & 435.1 & $357 \pm 81 * * *$ & 276.5 \\
\hline Total bilirubin, $\mu \mathrm{mol} / \mathrm{L}$ & $6.07 \pm 1.67$ & $3.61 \pm 0.88^{*}$ & 59.5 & $8.22 \pm 1.32$ & 135.3 \\
\hline Glucose, $\mathrm{mmol} / \mathrm{L}$ & $7.39 \pm 1.04$ & $6.57 \pm 0.76$ & 89.0 & $6.17 \pm 0.55$ & 83.5 \\
\hline Total calcium, $\mathrm{mmol} / \mathrm{L}$ & $2.53 \pm 0.09$ & $2.69 \pm 0.20$ & 106.2 & $2.67 \pm 0.14$ & 105.5 \\
\hline Non-organic phosphorus, $\mathrm{mmol} / \mathrm{L}$ & $3.07 \pm 0.58$ & $3.43 \pm 0.25$ & 111.6 & $2.47 \pm 0.42$ & 80.3 \\
\hline $\mathrm{Ca} / \mathrm{P}$ & $0.843 \pm 0.129$ & $0.800 \pm 0.076$ & 94.9 & $1.117 \pm 0.195 *$ & 132.5 \\
\hline Gamma-glutamyl transferase (GGT), U/L & $9.29 \pm 2.60$ & $7.86 \pm 2.17$ & 84.6 & $5.83 \pm 0.69 * *$ & 62.8 \\
\hline Cholesterol, $\mathrm{mmol} / \mathrm{L}$ & $1.27 \pm 0.14$ & $1.41 \pm 0.14$ & 111.2 & $1.63 \pm 0.11 * * *$ & 128.5 \\
\hline Triglycerides, $\mathrm{mmol} / \mathrm{L}$ & $2.129 \pm 0.547$ & $1.429 \pm 0.306^{*}$ & 67.1 & $0.850 \pm 0.299^{* * *}$ & 39.9 \\
\hline $\mathrm{HDL}, \mathrm{mmol} / \mathrm{L}$ & $0.650 \pm 0.128$ & $0.843 \pm 0.243$ & 129.6 & $1.865 \pm 0.115^{* * *}$ & 286.9 \\
\hline $\mathrm{LDL}, \mathrm{mmol} / \mathrm{L}$ & $0.517 \pm 0.290$ & $0.605 \pm 0.149$ & 117.0 & $0.350 \pm 0.064$ & 67.7 \\
\hline Atherogenic index of plasma (AIP), U. & $1.04 \pm 0.45$ & $0.86 \pm 0.49$ & 82.2 & $0.24 \pm 0.18^{* * *}$ & 23.1 \\
\hline C-reactive protein (CRP), $\mathrm{mg} / \mathrm{L}$ & $12.5 \pm 5.4$ & $15.5 \pm 4.6$ & 123.6 & $9.3 \pm 1.9$ & 74.3 \\
\hline
\end{tabular}

Note: see Table 1. 
Table 4

Change in $\mathrm{CBC}$ and WBC differential of male rats under effect of addition to $S$. officinalis $\mathrm{L}$. and $S$. sclarea $\mathrm{L}$. ( $\mathrm{x} \pm \mathrm{SD}, \mathrm{n}=8$, duration of experiment 30 days)

\begin{tabular}{|c|c|c|c|c|c|}
\hline Parameter & Control & S. officinalis & S. officinalis compared to the control, $\%$ & S. sclarea & S. sclarea compared to the control, $\%$ \\
\hline Hemoglobin, g/L & $126.8 \pm 7.0$ & $133.8 \pm 9.5$ & 105.5 & $112.7 \pm 12.0$ & 88.8 \\
\hline Hematocrit, \% & $40.5 \pm 2.7$ & $43.0 \pm 3.3$ & 106.3 & $35.4 \pm 3.9$ & 87.3 \\
\hline Erythrocytes, $10^{12} / \mathrm{L}$ & $6.93 \pm 0.29$ & $7.74 \pm 0.46$ & 111.7 & $6.22 \pm 0.55$ & 89.7 \\
\hline Erythrocyte sedimentation rate (ESR), $\mathrm{mm} / \mathrm{h}$ & $1.17 \pm 0.39$ & $1.00 \pm 0.00$ & 85.7 & $1.00 \pm 0.00$ & 85.7 \\
\hline Thrombocytes, $10^{9} / \mathrm{L}$ & $339 \pm 66$ & $349 \pm 41$ & 103.1 & $283 \pm 40$ & 83.6 \\
\hline WBC, $10^{9} / \mathrm{L}$ & $8.6 \pm 1.6$ & $11.1 \pm 3.4$ & 129.0 & $9.4 \pm 3.3$ & 109.7 \\
\hline \multicolumn{6}{|l|}{ WBC differential } \\
\hline Basophils, \% & $0.0 \pm 0.0$ & $0.0 \pm 0.0$ & 0.0 & $0.0 \pm 0.0$ & 0.0 \\
\hline Eosinophils, \% & $1.50 \pm 0.76$ & $0.83 \pm 0.90$ & 55.6 & $1.00 \pm 0.58$ & 66.7 \\
\hline Eosinophils, \% & $0.0 \pm 0.0$ & $0.0 \pm 0.0$ & 0.0 & $0.0 \pm 0.0$ & 0.0 \\
\hline \multicolumn{6}{|l|}{ Neutrophils, \%: } \\
\hline -young & $0.0 \pm 0.0$ & $0.0 \pm 0.0$ & 0.0 & $0.0 \pm 0.0$ & 0.0 \\
\hline - band & $1.17 \pm 0.69$ & $0.67 \pm 0.47$ & 57.1 & $0.17 \pm 0.37$ & 14.3 \\
\hline - with segmented nuclei & $23.0 \pm 8.2$ & $18.8 \pm 3.8$ & 81.9 & $21.7 \pm 6.2$ & 94.2 \\
\hline Lymphocytes, \% & $68.8 \pm 8.6$ & $73.0 \pm 3.8$ & 106.1 & $73.2 \pm 8.0$ & 106.3 \\
\hline Monocytes, \% & $5.50 \pm 1.26$ & $6.67 \pm 0.94$ & 121.2 & $4.00 \pm 1.83$ & 72.7 \\
\hline
\end{tabular}

Note: no statistically significant changes were found between samples.

There were no significant changes in the open field test between the groups and within groups at the beginning and the end of the experiment (Table 5), except for the group of rats that ate dry shoots of $S$. officinalis according to the number of peripheral squares that they visited (decrease from $24.9 \pm 7.8$ to $6.1 \pm 6.6$ ).

\section{Discussion}

In modern scientific medicine, sage herb is used very broadly. Scientific studies have revealed antitumour, anti-inflammatory, analgesic, antioxidant, antibacterial, antimutagenic, hypoglycemic, neuroprotective, hypolipidemic properties of sage extracts (Hamidpour et al., 2014; Monsefi et al., 2015, 2017). Sage contains essential oil, coumarins, alkaloids, flavonoids, saponins, sclareol, rosmarinic acid, dihydroquercetin, rutin, coumarin, umbelliferone, gallic, chicoric and ferulic acids, salts of $\mathrm{K}, \mathrm{Ca}, \mathrm{Fe}, \mathrm{Mn}$, $\mathrm{Zn}, \mathrm{Li}, \mathrm{Sn}$, and also identified polyphenols, phenolic and flavonoid glycosides. Of the phenolic substances, glycosides of luteolin (42\%) and apige$\operatorname{nin}(27 \%)$ were identified, the main volatile compounds of the extract were $\alpha$-thujone (32.3\%), camphor (29.7\%), 1,8-cineole $(6.2 \%)$ and humulene (5.1\%).

Bioactive hydrophobic diterpene in the composition of the essential oil from S. sclarea is sclareol, it is broadly studied for its anti-inflammatory and antioxidant effects (Cerri et al., 2019). Cerri et al. (2019) did a very similar study to the one we did, where one of the randomly composed groups of Swiss male mice was fed standard diet (STD) and the other one received high-fat diet (HFD). After obesity in the mice had been induced, three treatment groups were made out of each of the two: free sclareol (Sc), sclareol-loaded lipid nanoparticle (L-Sc) and empty lipid nanoparticle (L). Treatments were conducted every day for the period of 30 days. The study revealed that L-Sc had positive effects on metabolic profiles in obese mice by decreasing adiposity, improving insulin sensitivity, tolerance to the glucose and increasing the HDL plasma levels. Furthermore, L-Sc caused decreases in the expressions of NF-KB, MCP-1 and SERBP-1. Combination treatment using sclareol and lipid nanocarriers, which can reduce adipose tissues, could be effective against metabolic disorders.

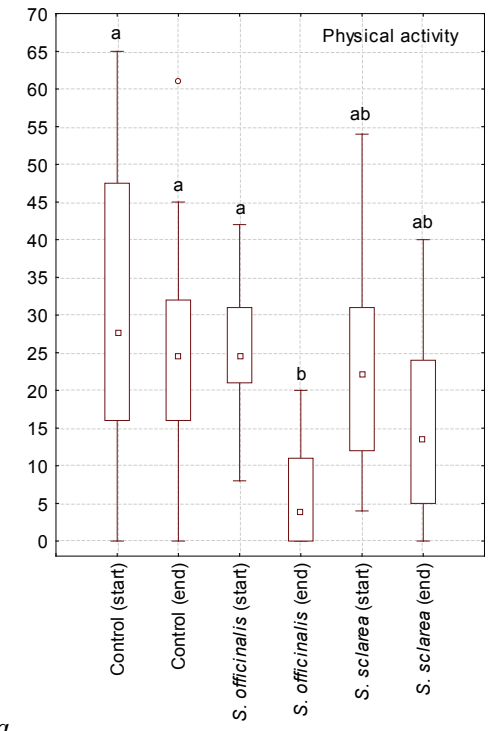

$a$

Fig. 2. Changes in the motor $(a)$ and orientational activity $(b)$, as well as the emotional status $(c)$ of male rats when Salvia officinalis $\mathrm{L}$. and $S$. sclarea L. chopped shoots were added to their diet: on the abscissa - groups of animals $\left(n=n_{1} * n_{2}=32: n_{1}=8\right.$ animals, $n_{2}=4$ experiments with each animal) on a high fat diet with and the addition of shredded herbal shoots (the days after the start of the experiment are indicated in parentheses: 1-4th or 26-30th), on the ordinate axis - the absolute number of markers of this behaviour type in 120 seconds of the experiment: for physical activity the number of visited squares of the open field, for orientational activity - the number of standings upright, for emotional status - the number of grooming actions, defecation and urination; small square - median, upper and lower borders of the rectangle $-25 \%$ and $75 \%$ quartiles, vertical line-minimum and maximum values, circles - outliers; different letters within each figure indicate significant differences between groups $(\mathrm{P}<0.05)$ according to the results of the Tukey test 
In our study, the two sage species showed the opposite effect on weight gain rats that received high-fat diet. Thus, the addition of S. officinalis dry crushed shoots led to sharp increase in the rats' body weight during the 30-day experiment, while the addition of $S$. sclarea, on the contrary, slowed down the weight gain both in comparison with the control and the first experimental group. This fact is of interest, since at the same time a decrease in food intake was observed in the group of rats that consumed $S$. officinalis, in comparison with the control group and animals that consumed $S$. sclarea.

An indicator that is often used as a sensitive index for assessing the toxic effects of various substances, including medicinal ones, is the mass of the organs (Balogun et al., 2014; Varcholyak \& Gutyi, 2019). Increase in the total body weight against the background of high-fat diet is accompanied by increase in the absolute mass of the internal organs, while the relative mass may not always increase. In our experiment, the intake of sage led to significant decrease in the relative mass of the immune system organs (thymus and spleen), but no changes in the composition of the blood (WBC count, WBC differential) were found. In the studies by Tkachuk \& Shapoval (1987), it was also indicated that S. sclarea essential oils affects the immune system, as well as the fermentative activity of the blood. In our experiment, we also observed change in the enzymatic activity of the rats' blood when chopped sage was added to the high-fat diet. Thus, the consumption of $S$. officinalis caused a strong increase in the activity of alkaline phosphatase, and consumption of $S$. sclarea caused moderate increase, while the activity of AST and ALT did not significantly differ from those of the control animals. Also, in comparison with the control group, the rats of the first experimental group were observed to have insignificant decrease in the activity of gamma-glutamyl transferase, whereas in the second group this parameter significantly and reliably decreased; this indicator was within the reference values in all the groups.

\section{Table 5}

Change in behavioural characteristics of three rats groups during 2 minutes of the experiment, in which diet Salvia officinalis L. and $S$. sclarea $\mathrm{L}$. was added $(x \pm S D, n=32$, duration of the experiment was 30 days)

\begin{tabular}{|c|c|c|c|c|c|c|}
\hline Feature & $\begin{array}{l}\text { Control, } \\
\text { 1-4th days }\end{array}$ & $\begin{array}{c}\text { Control, } \\
\text { 26-30th days }\end{array}$ & $\begin{array}{c}\text { S. officinalis, } \\
\text { 1-4th days }\end{array}$ & $\begin{array}{l}\text { S. officinalis, } \\
\text { 26-30th days }\end{array}$ & $\begin{array}{l}\text { S. sclarea, } \\
\text { 1-4th days }\end{array}$ & $\begin{array}{c}\text { S. sclarea, } \\
\text { 26-30th days }\end{array}$ \\
\hline Number of visited peripheral squares & $28.1 \pm 18.0^{\mathrm{a}}$ & $24.3 \pm 14.5^{\mathrm{a}}$ & $24.9 \pm 7.8^{\mathrm{a}}$ & $6.1 \pm 6.6^{b}$ & $22.0 \pm 12.3^{\mathrm{ab}}$ & $15.4 \pm 11.7^{\mathrm{ab}}$ \\
\hline Number of visited central squares & $1.000 \pm 2.341$ & $0.292 \pm 1.042$ & $0.500 \pm 2.134$ & $0.000 \pm 0.000$ & $0.542 \pm 1.285$ & $0.167 \pm 0.565$ \\
\hline Number of upright stands in peripheral squares & $5.58 \pm 4.53$ & $3.79 \pm 3.13$ & $4.50 \pm 2.89$ & $1.96 \pm 1.67$ & $2.79 \pm 1.74$ & $2.29 \pm 1.71$ \\
\hline Number of upright stands in central squares & $1.292 \pm 1.429$ & $0.708 \pm 0.999$ & $1.143 \pm 1.533$ & $0.071 \pm 0.378$ & $1.250 \pm 1.294$ & $1.042 \pm 1.233$ \\
\hline Number of grooming acts & $0.583 \pm 0.830$ & $0.583 \pm 0.929$ & $1.214 \pm 1.475$ & $0.143 \pm 0.356$ & $0.833 \pm 1.761$ & $0.792 \pm 1.560$ \\
\hline Number of faecal bolus & $2.250 \pm 2.027$ & $2.375 \pm 1.555$ & $2.036 \pm 1.795$ & $2.536 \pm 2.646$ & $0.500 \pm 0.722$ & $0.542 \pm 1.021$ \\
\hline Number of urinations & $0.333 \pm 0.482$ & $0.375 \pm 0.495$ & $0.071 \pm 0.262$ & $0.107 \pm 0.315$ & $0.042 \pm 0.204$ & $0.042 \pm 0.204$ \\
\hline
\end{tabular}

Note: there were no significant differences between the groups for most of the parameters studied; differences in the number of visited peripheral squares are indicated by different Latin letters $(\mathrm{P}<0.05)$ according to the Tukey test results with Bonferroni correction.

In studies that were carried out on broiler chickens, sage powder of S. officinalis was added to the diet in the doses of 4 and $8 \mathrm{~g} / \mathrm{kg}$, its effect on the immune organs and blood biochemical parameters was indicated. Such a diet did not affect the ratio of albumin and globulins and the ratio of granulocytes and blood lymphocytes, as well as the concentration of cholesterol, HDL and LDL. At the same time, a high concentration of the sage powder $(8 \mathrm{~g} / \mathrm{kg})$ significantly increased the relative mass of the cloacal bursa in poultry, and also led to a decrease in the concentration of total protein and triglycerides in the blood serum (Toghyani et al., 2012).

A study by Ekin et al. (2019) focused on antialzheimer, antidiabetic, antioxidant and antiobesity activities of ethanol extracts from $S$. sclarea. Leaf extract of $S$. sclarea significantly inhibited butyrylcholinesterase $(51.76 \pm 1.04 \%)$. The Salvia species demonstrated the highest total antioxidant activity. Extracts from flowers of $S$. sclarea $(1.34 \pm 0.08)$ and leaves $(1.34 \pm 0.08)$ exihibited high ferric-reducing antioxidant power. Extracts of $S$. sclarea displayed notable inhibitory activity and are considered possible sources of alpha-glucosidase inhibitors (Ekin et al., 2019).

The most active chemotype of $S$. sclarea was determined by monitorring the acute and subchronic antidiabetic activities of essential oils along with linalool and linalyl acetate. Plants of chemotypes 1 (linalool content), which grow on low altitudes in Lebanon and Poland, was seen to have significantly higher acute and subchronic antidiabetic activities compared with chemotype 5 (high linalyl acetate content). Essential oils from S. sclarea demonstrated potential antidiabetic activities, and may be used as a complementary or alternative treatment of diabetes and complications that accompany it (Raafat \& Habib, 2018; Pereira et al., 2019; Salehi et al., 2020; Abu-Odeh \& Talib, 2021).

In studies by Agadzhanyan (2015) on human blood serum with a glucose concentration of $10.0 \mathrm{mmol} / \mathrm{L}$ and a total cholesterol level of $8.2 \mathrm{mmol} / \mathrm{L}$ in vitro, the hypoglycemic and hypolipidemic activity of S. officinalis leaf extracts was investigated. The results revealed both aqueous and alcoholic extracts of the studied plant being effective in reducing glucose concentration and serum cholesterol levels (Bassil et al., 2015). In studies on mice with diet-induced obesity, ethanolic sage extract caused rosiglitazone-like effect, improved insulin sensitivity, inhibited adipocyte lipogenesis, and reduced inflammation (Ben Khedher et al., 2018).

In our study, in rats on a high-fat diet, the glucose level was at the upper level of the reference range, and the addition of sage to the feed led to a slight and insignificant decrease in the blood glucose. At the same time, the indicators of fat metabolism in animals were significantly altered by the consumption of $S$. sclarea. Thus, in comparison with the control group, the rats of the second experimental group (that consumed S. sclarea) had an increase in cholesterol levels, a sharp increase in the concentration of high-density lipoproteins and a decrease in low-density lipoproteins, which led to a sharp significant decrease of the atherogenic index.

In our previous study (Zazharskyi et al., 2019), we observed a high activity of an alcoholic tincture of the $S$. sclarea against Escherichia coli and Proteus vulgaris, and, at the same time, a very low activity against Salmonella typhimurium, Klebsiella pneumoniae, Listeria monocytogenes, Corynebacterium xerosis and fungus Candida albicans.

A study (Yang et al., 2014) of efficiency of S. sclarea in treatment of endothelial dysfunction induced by chronic immobilization stress in rats demonstrated that treatment with $5 \%, 10 \%$, and $20 \%$ S. sclarea significantly decreased systolic blood pressure. Treatment with $20 \%$ S. sclarea also significantly reduced the heart rate compared with the group that had chronic immobilization stress (Yang et al., 2014). Also, S. sclarea caused decreases in corticosterone $(10 \%$ and $20 \%)$ and malondialdehyde $(10 \%$, $20 \%$ ) in serum. Similar results were observed with nifedipine. Moreover, $20 \%$ S. sclarea provoked significant increases in nitric oxide production and eNOS expression level and relaxed aortic rings in rats suffering stress from chronic immobilization (Yang et al., 2014). By increasing production of NO and eNOS level, as well as decreasing oxidative stress, treatment of rats that were under immobilization stress with $S$. sclarea led to their recovery from endothelial dysfunction. Therefore, treatment of endothelial dysfunction with appropriate $S$. sclarea concentration could lead to recovery. These data indicate that oil from $S$. sclarea may be efficient in prophylaxis and treatment of stress-induced cardiovascular diseases (Yang et al., 2014).

In studies by El-Shafeial et al. (2013), against the background of pathological and toxic changes in the body of mice caused by the action of carbon tetrachloride, the use of $S$. officinalis oil before and after carbon tetrachloride had a levelling effect on the state of the liver and kidneys, and there was also a tendency towards restoration of their functions. At the same time, the preventive use of oils was less effective. Essential oil isolated from $S$. sclarea inhibited growth of HeLa cells with an $\mathrm{IC}_{50}$ of $80.69=0.01 \mu \mathrm{g} / \mathrm{mL}$. Staining with propidium iodide (PI) showed the 
presence of apoptosis in cells that were treated with oil (Durgha et al., 2016). Treatments with essential oil from $S$. sclarea in different concentrations reduced inflammation (Durgha et al., 2016). However, histopathological assay of the liver tissue treated with $1.5 \mu \mathrm{g}$ lipopolysaccharide (LPS)/30 $\mathrm{g}$ body weight of BALB/c mice revealed severe inflammation and necrosis. Hepatocytes' necrosis and infiltration were barely seen after using $100 \mu \mathrm{g}$ of essential oil of S. sclarea (Durgha et al., 2016).

The influence of sage and medicinal preparations made with it on the nervous system attracts considerable interest of researchers (Cavalcante et al., 2018; Dinel et al., 2020). Ther study revealed significant neuroprotection in the MTT assay by $39.5 \%$ and inhibition of intracellular ROS by $61.4 \%$ caused by eighty percent methanol extracts of $S$. sclarea in $100 \mu \mathrm{g} / \mathrm{mL}$ concentration (Tavakkoli et al., 2014). In the future, researchers may discover new natural therapeutic agents for treating disorders such as Alzheimer and Parkinson diseases (Tavakkoli et al., 2014). A group of female patients exposed to vapours of $S$. sclarea essential oil were observed to have a significant decreases in systolic blood pressure, diastolic blood pressure and respiratory rate compared with the control (Seol et al., 2013). Inhaling S. sclarea essential oil statistically significantly reduced the respiratory rate.

Salvia sclarea oil contains two times more omega-3 fatty acids than other Salvia species, which take part in eicosanoid synthesis and contain significant levels of monoterpane linalool, a psychoactive ingredient (Gross et al., 2013). In dominant mice, pregnant mothers of which received S. sclarea oil-enriched food from the date of conception, dominant and anxiety behaviour significantly decreased, compared with their counterparts treated with sunflower oil. A similar tendency and a prominent reduction in blood corticosterone levels were seen in submissive mice treated with S. sclarea oil (Gross et al., 2013). These data and findings confirm the hypothesis that $S$. sclarea oil has anxiolytic properties.

In the study, where rats were intraperitoneally injected or inhaled essential oils (Seol et al., 2010), 5\% (v/v) S. sclarea oil had the strongest antistress effect in rats during the forced swim test. However, pre-treatment with buspirone (a 5-HT1A agonist), SCH-23390 (a D-1 receptor antagonist) and haloperidol (a D-2, D-3, and D-4 receptor antagonist) significantly blocked the anti-stress effect of $S$. sclarea oil (Seol et al., 2010). The antidepressant-like effect taken by oil from $S$. sclarea oil is related to the modulation of the dopaminergic pathway.

In our study, the behavioural responses of rats from the experimental groups which consumed dry crushed sage shoots with high-fat diet had changed by the end of the experiment compared with the control group. Thus, consuming $S$. officinalis caused only significant decrease in rats' physical activity. At the same time, S. sclarea caused decrease of physical activity at the level of tendency, significant decrease in orientational activity, and decrease in the emotional status of experimental animals.

Therefore, further research will be aimed at studying the effects of different doses of extracts from these medicinal plants ( $S$. officinalis and S. sclarea) on the organism of laboratory animals during various metabolic disorders at the tissue, cellular and subcellular levels.

\section{Conclusions}

The addition of closely related sage species from the same genus (Salvia officinalis L. and S. sclarea L.) to the food of rats caused multidirectional changes in their metabolism. The addition of S. officinalis to the diet led to sharp increase in body weight (up to $130.8 \%$ of the initial weight for 30 days of the experiment). The body weight of the rats that had been treated with S. sclarea increased only by $103.8 \%$ of their initial weight and was lower than in the control group. Oil from $S$. officinalis increased daily weight gain up to $1771 \mu \mathrm{g} /$ day $(253.1 \%$ of the control group), and $S$. sclarea - decreased it to $194 \mu \mathrm{g} /$ day $(27.8 \%$ of the control group). In the group that had received S. officinalis, the relative weight of the brain (77.7\% of control), spleen (80.4\%), and thymus (59.1\%) decreased. In the group treated with $S$. sclarea, the relative weight of the thymus decreased $(43.4 \%)$ and the relative weight of the colon increased ( $159.7 \%$ to the control group).

Under the influence of $S$. officinalis, the concentrations of urea (78.3\%), total bilirubin (59.5\%) and triglycerides (67.1\%) decreased, and the concentration of total protein $(109.8 \%)$ and the activity of alkaline phosphatase (435.1\% of control) increased. Consumption of $S$. sclarea shoots increased the activity of alkaline phosphatase (276.5\%), drastically decreases the atherogenic index ( $23.1 \%$ of the level of the control group) as a result of increasing the concentration of high density lipoprotein cholesterol $(286.9 \%)$ and decreasing the concentration of low density lipoprotein cholesterol (67.7\%). Also, in rats that had received S. sclarea, we observed increase in the concentration of cholesterol (128.5\%) and decrease in the concentration of triglycerides (39.9\%), decrease in the activity of gamma-glutamyl transferase $(62.8 \%)$ and increase in the $\mathrm{Ca} / \mathrm{P}$ ratio (up to $132.5 \%$ of the control group). No significant changes were observed in CBC and WBC differential of male rats that consumed S. officinalis and S. sclarea shoots.

According to the results of the open field test, the physical and orientational activity of male rats under the influence of $S$. officinalis significantly decreased by the end of the experiment. Emotional status of rats, on the contrary, decreased when they ate $S$. sclarea dry crushed shoots in the composition of their food.

Thus, excess body weight against the background of hypercaloric diet in rats led, in general, to more pronounced deviations from the norm when the animals ate $S$. officinalis dry crushed shoots. And vice versa, the addition of dry crushed shoots of $S$. sclarea to the diet of animals normalized body weight in comparison with the control group, and reduced the negative manifestations of obesity at the biochemical and organismal levels. According to these results, the substances contained in S. sclarea should be carefully studied for anti-atherosclerotic activity, and tea supplemented with $S$. sclarea shoots can be recommended as a corrective supplement in the diet of overweight people.

\section{References}

Abu-Odeh, A. M., \& Talib, W. H. (2021). Middle East medicinal plants in the treatment of diabetes: A review. Molecules, 26(3), 742.

Agadzhanyan, A. A. (2015). Hypoglycemic and hypolipidemic activity of the leaf extract of Salvia officinalis L. Eurasian Union of Scientists, Series: Medical, Biological and Chemical Sciences, 12(21), 5-8.

AlMotwaa, S. M., Alkhatib, M. H., \& Alkreathy, H. M. (2020). Incorporating ifosfamide into Salvia oil-based nanoemulsion diminishes its nephrotoxicity in mice inoculated with tumor. Biolmpacts, 10(1), 9-16.

Bassil, M., Daher, C. F., Mroueh, M., \& Zeeni, N. (2015). Salvia libanotica improves glycemia and serum lipid profile in rats fed a high fat diet. BMC Complementary and Alternative Medicine, 15, 384.

Ben Khedher, M. R., Hammami, M., Arch, J., Hislop, D. C., Eze, D., Wargent, E. T., Kępczyńska, M. A., \& Zaibi, M. S. (2018). Preventive effects of Salvia officinalis leaf extract on insulin resistance and inflammation in a model of high fat dietinduced obesity in mice that responds to rosiglitazone. PeerJ, 6, e4166.

Bibi, M., Choudhary, M. I., \& Yousuf, S. (2020). Crystal structure and hirshfeld surface analysis of the methanol solvate of sclareol, a labdane-type diterpenoid. Acta Crystallographica Section E-Crystallographic Communications, 76, 294.

Bilan, M. V., Lieshchova, M. A., Tishkina, N. M., \& Brygadyrenko, V. V. (2019). Combined effect of glyphosate, saccharin and sodium benzoate on the gut microbiota of rats. Regulatory Mechanisms in Biosystems, 10(2), 228-232.

Boyko, A. A., \& Brygadyrenko, V. V. (2016). Influence of water infusion of medicinal plants on larvae of Strongyloides papillosus (Nematoda, Strongyloididae). Visnyk of Dnipropetrovsk University, Biology, Ecology, 24(2), 519-525.

Bozok, F., \& Ulukanli, Z. (2016). Volatiles from the aerial parts of east mediterranean clary sage: Phytotoxic activity. Joumal of Essential Oil Bearing Plants, 19(5), 1192-1198.

Brygadyrenko, V. V., Lieshchova, M. A., Bilan, M. V., Tishkina, N. M., \& Horchanok, A. V. (2019). Effect of alcohol tincture of Aralia elata on the organism of rats and their gut microbiota against the background of excessive fat diet. Regulatory Mechanisms in Biosystems, 10(4), 497-506.

Cavalcante E Costa, G. F., Nishijo, H., Caixeta, L. F., \& Aversi-Ferreira, T. A. (2018). The confrontation between ethnopharmacology and pharmacological tests of medicinal plants associated with mental and neurological disorders. Evidence-Based Complementary and Alternative Medicine, 2018, 7686913.

Cerri, G. C., Lima, L. C. F., Lelis, D. D., Barcelos, L. D., Feltenberger, J. D., Mussi, S. V., Monteiro, R. S., dos Santos, R. A. S., Ferreira, L. A. M., \& Santos, S. H. S. (2019). Sclareol-loaded lipid nanoparticles improved metabolic profile in obese mice. Life Sciences, 218, 292-299.

Ceschel, G. C., Maffei, P., Moretti, M. D. L., Peana, A. T., \& Demontis, S. (1998). In vitro permeation through porcine buccal mucosa of Salvia sclarea L. essential oil from topical formulations. STP Pharma Sciences, 8(2), 103-106.

Chen, Q., Tang, K., \& Guo, Y. (2020). Discovery of sclareol and sclareolide as filovirus entry inhibitors. Journal of Asian Natural Products Research, 22(5), $464-473$. 
Cui, H. Y., Zhang, X. J., Zhou, H., Zhao, C. T., \& Lin, L. (2015). Antimicrobial activity and mechanisms of Salvia sclarea essential oil. Botanical Studies, 56, 16.

Dinel, A. L., Lucas, C., Guillemet, D., Layé, S., Pallet, V., \& Joffre, C. (2020). Chronic supplementation with a mix of Salvia officinalis and Salvia lavandulaefolia improves morris water maze learning in normal adult $\mathrm{C} 57 \mathrm{Bl} / 6 \mathrm{~J}$ mice. Nutrients, 12(6), 1777.

Dogan, H. (2020). Minerals and bioactive content of some Salvia species in cultivated condition. Comptes Rendus de L Academie Bulgare des Sciences, 73(10), 1398-1408

Durgha, H., Thirugnanasampandan, R., Ramya, G., \& Ramanth, M. G. (2016). Inhibition of inducible nitric oxide synthase gene expression (iNOS) and cytotoxic activity of Salvia sclarea L. essential oil. Journal of King Saud University Science, 28(4), 390-395.

Ekin, H. N., Deliorman Orhan, D., Erdocan Orhan, I., Orhan, N., \& Aslan, M. (2019). Evaluation of enzyme inhibitory and antioxidant activity of some Lamiaceae plants. Journal of Research in Pharmacy, 23(4), 749-758.

El-Gohary, A. E., Amer, H. M., Salama, A. B., Wahba, H. E., \& Khalid, K. A. (2020). Characterization of the essential oil components of adapted Salvia sclarea L. (clary sage) plant under Egyptian environmental conditions. Journal of Essential Oil Bearing Plants, 23(4), 788-794.

El-Shafei, S. M. A., Abd El-Rahman, A. A., Tukhbatova, R. I., Ivanova, E. V., Akinina, E. A., Voronkova, Y. E., Bukuru, L. K., Fattakhova, A. N., Alimova, F. K. (2013). Effect of plant oils Nigella sativa and Salvia officinalis on the biochemical indices of CD-1 mice. Scientific Notes of Kazan University, 155(3), 82-89.

Erisen, S., Kurt-Gur, G., \& Servi, H. (2020). In vitro propagation of Salvia sclarea L. by meta-topolin, and assessment of genetic stability and secondary metabolite profiling of micropropagated plants. Industrial Crops and Products, 157, 112892.

Fiore, G., Nencini, C., Cavallo, F., Capasso, A., Bader, A., Giorgi, G., \& Micheli, L. (2006). In vitro antiproliferative effect of six Salvia species on human tumor cell lines. Phytotherapy Research, 20(8), 701-703.

Firuzi, O., Miri, R., Asadollahi, M., Eslami, S., \& Jassbi, A. R. (2013). Cytotoxic, antioxidant and antimicrobial activities and phenolic contents of eleven Salvia species from Iran. Iranian Journal of Pharmaceutical Research, 12(4), 801-810.

Francik, S., Francik, R., Sadowska, U., Bystrowska, B., Zawiślak, A., Knapczyk, A., \& Nzeyimana, A. (2020). Identification of phenolic compounds and determination of antioxidant activity in extracts and infusions of Salvia leaves. Materials, 13(24), 5811.

Fraternale, D., Giamperi, L., Bucchini, A., Ricci, D., Epifano, F., Genovese, S., \& Curini, M. (2005). Composition and antifungal activity of essential oil of Salvia sclarea from Italy. Chemistry of Natural Compounds, 41(5), 604-606.

Ghowsi, M., Yousofvand, N., \& Moradi, S. (2020). Effects of Salvia officinalis L. (common sage) leaves tea on insulin resistance, lipid profile, and oxidative stress in rats with polycystic ovary: An experimental study. Avicenna Journal of Phytomedicine, 10(3), 263-272.

Grigoriadou, K., Trikka, F. A., Tsoktouridis, G., Krigas, N., Sarropoulou, V., Papanastasi, K., Maloupa, E., \& Makris, A. M. (2020). Micropropagation and cultivation of Salvia sclarea for essential oil and sclareol production in Northern Greece. In Vitro Cellular and Developmental Biology - Plant, 56(1), 51-59.

Gross, M., Nesher, E., Tikhonov, T., Raz, O., \& Pinhasov, A. (2013). Chronic food administration of Salvia sclarea oil reduces animals' anxious and dominant behavior. Journal of Medicinal Food, 16(3), 216-222.

Gunnewich, N., Higashi, Y., Feng, X. H., Choi, K. B., Schmidt, J., \& Kutchan, T. M. (2013). A diterpene synthase from the clary sage Salvia sclarea catalyzes the cyclization of geranylgeranyl diphosphate to (8R)-hydroxy-copalyl diphosphate. Phytochemistry, 91, 93-99.

Hamidpour, M., Hamidpour, R., Hamidpour, S., \& Shahlari, M. (2014). Chemistry, pharmacology, and medicinal property of sage (Salvia) to prevent and cure illnesses such as obesity, diabetes, depression, dementia, lupus, autism, heart disease, and cancer. Journal of Traditional and Complementary Medicine, 4(2), 82-88.

Han, S. H., Hur, M. H., Buckle, J., Choi, J., \& Lee, M. S. (2006). Effect of aromatherapy on symptoms of dysmenornea in college students: A randomized placebocontrolled clinical trial. Journal of Alternative and Complementary Medicine, 12(6), 535-541.

Hanganu, D., Olah, N. K., Pop, C. E., Vlase, L., Oniga, I., Ciocarlan, N., Matei, A., Puscas, C., Silaghi-Dumitrescu, R., \& Benedec, D. (2019). Evaluation of polyphenolic profile and antioxidant activity for some Salvia species. Farmacia, 67(5), 801-805.

Hudz, N., Yezerska, O., Shanaida, M., Sedlackova, V. H., \& Wieczorek, P. P. (2019). Application of the Folin-Ciocalteu method to the evaluation of Salvia sclarea extracts. Pharmacia, 66(4), 209-215.

Jakovljević, M., Jokić, S., Molnar, M., Jašić, M., Babić, J., Jukić, H., \& Banjari, I. (2019). Bioactive profile of various Salvia officinalis L. preparations. Plants, $8(3), 55$.

Jasicka-Misiak, I., Poliwoda, A., Petecka, M., Buslovych, O., Shlyapnikov, V. A., \& Wieczorek, P. P. (2018). Antioxidant phenolic compounds in Salvia officinalis L. and Salvia sclarea L. Ecological Chemistry and Engineering, 25(1), 133-142.
Jia, M. R., O’Brien, T. E., Zhang, Y., Siegel, J. B., Tantillo, D. J., \& Peters, R. J. (2018). Changing face: A key residue for the addition of water by sciareol synthase. ACS Catalysis, 8(4), 3133-3137.

Jin, H. M., Shao, Z. X., Wang, Q. Q., Miao, J. S., Bai, X. Q., Liu, Q., Qiu, H., Wang, C., Zhang, Z. J., Jennifer, T., Wang, X. Y., \& Xu, J. K. (2019). Sclareol prevents ovariectomy-induced bone loss in vivo and inhibits osteoclastogenesis in vitro via suppressing NF-kappa B and MAPK/ERK signaling pathways. Food and Function, 10(10), 6556-6567.

Karayel, H. B. (2020). Effect of natural boron mineral use on the essential oil ratio and components of musk sage (Salvia sclarea L.). Open Chemistry, 18(1), 732-739.

Karayel, H. B., \& Akcura, M. (2019). Examination of the changes in components of the volatile oil from Abyssinian sage, musk sage and medical sage [Salvia aethiopis L., Salvia sclarea L. and Salvia officinalis L. (hybrid)] growing in different locations. Grasas y Aceites, 70(3), e319.

Kosti, M., Kitic, D., Petrovic, M. B., Jevtovic-Stoimenov, T., Jovic, M., Petrovic, A., \& Zivanovic, S. (2017). Anti-inflammatory effect of the Salvia sclarea L. ethanolic extract on lipopolysaccharide-induced periodontitis in rats. Journal of Ethnopharmacology, 199, 52-59.

Kostova, I., Lasheva, V., Fidan, H., Georgieva, D., Damyanova, S., \& Stoyanova, A (2020). Effect of clary sage (Salvia sclarea L.) essential oil on paper packaging materials. Ukrainian Food Journal, 9(2), 287-297.

Kuzma, L., Derda, M., Hadas, E., \& Wysokinska, H. (2015). Abietane diterpenoids from Salvia sclarea transformed roots as growth inhibitors of pathogenic Acanthamoeba spp. Parasitology Research, 114(1), 323-327.

Lieshchova, M. A., \& Brygadyrenko, V. V. (2021). Influence of Lavandula angustifolia, Melissa officinalis and Vitex angus-castus on the organism of rats fed with excessive fat-containing diet. Regulatory Mechanisms in Biosystems, 12(1), 169-180.

Lieshchova, M. A., Bilan, M. V., Bohomaz, A. A., Tishkina, N. M., \& Brygadyrenko, V. V. (2020). Effect of succinic acid on the organism of mice and their intestinal microbiota against the background of excessive fat consumption. Regulatory Mechanisms in Biosystems, 11(2), 153-161.

Lieshchova, M. A., Brygadyrenko, V. V., Tishkina, N. M., Gavrilin, P. M., \& Bohomaz, A. A. (2019). Impact of polyvinyl chloride, polystyrene, and polyethylene on the organism of mice. Regulatory Mechanisms in Biosystems, 10(1), 50-55.

Lieshchova, M. A., Tishkina, N. M., Bohomaz, A. A., Gavrilin, P. M., \& Brygadyrenko, V. V. (2018). Combined effect of glyphosphate, saccharin and sodium benzoate on rats. Regulatory Mechanisms in Biosystems, 9(4), 591-597.

Loizzo, M. R., Abouali, M., Salehi, P., Sonboli, A., Kanani, M., Menichini, F., \& Tundis, R. (2014). In vitro antioxidant and antiproliferative activities of nine Salvia species. Natural Product Research, 28(24), 2278-2285.

Mahboubi, M. (2020). Clary sage essential oil and its biological activities. Advances in Traditional Medicine, 20(4), 517-528.

Medeiros, A., Bianchi, S., Calvete, J. J., Balter, G., Bay, S., Robles, A., Cantacuzene, D., Nimtz, M., Alzari, P. M., \& Osinaga, E. (2000). Biochemical and functional characterization of the Tn-specific lectin from Salvia sclarea seeds. European Journal of Biochemistry, 267(5), 1434-1440.

Miliauskas, G., Venskutonis, P. R., \& van Beek, T. A. (2004). Screening of radical scavenging activity of some medicinal and aromatic plant extracts. Food Chemistry, 85(2), 231-237.

Mitic, M., Zmic, A., Wanner, J., \& Stappen, I. (2020). Clary sage essential oil and its effect on human mood and pulse rate: An in vivo pilot study. Planta Medica, 86(15), 1125-1132.

Monsefi, M., Abedian, M., Azarbahram, Z., \& Ashraf, M. J. (2015). Salvia officinali L. induces alveolar bud growing in adult female rat mammary glands. Avicenna Journal of Phytomedicine, 5(6), 560-567.

Monsefi, M., Nadi, A., \& Alinejad, Z. (2017). The effects of Salvia officinalis L. on granulosa cells and in vitro maturation of oocytes in mice. International Journal of Reproductive Biomedicine, 15(10), 649-660.

Noori, S., Hassan, Z. M., \& Salehian, O. (2013). Sclareol reduces CD4+ CD25+ FoxP3+ T-reg cells in a breast cancer model in vivo. Iranian Journal of Immunology, 10(1), 10-21.

Noori, S., Hassan, Z. M., Mohammadi, M., Habibi, Z., Sohrabi, N., \& Bayanolhagh, S. (2010). Sclareol modulates the Treg intra-tumoral infiltrated cell and inhibits tumor growth in vivo. Cellular Immunology, 263(2), 148-153.

Palchykov, V. A., Zazharskyi, V. V., Brygadyrenko, V. V., Davydenko, P. O., Kulishenko, O. M., Borovik, I. V., Chumak, V., Kryvaya, A., \& Boyko, O. O. (2019). Bactericidal, protistocidal, nematodicidal properties and chemical composition of ethanol extract of Punica granatum peel. Biosystems Diversity, 27(3), 300-306

Peana, A. T., Moretti, M. D. L., \& Juliano, C. (1999). Chemical composition and antimicrobial action of the essential oils of Salvia desoleana and S. sclarea. Planta Medica, 65(8), 752-754.

Pereira, A., Banegas-Luna, A. J., Peña-García, J., Pérez-Sánchez, H., \& Apostolides, Z (2019). Evaluation of the anti-diabetic activity of some common herbs and spices: Providing new insights with inverse virtual screening. Molecules, 24(22), 4030

Pitarokili, D., Couladis, M., Petsikos-Panayotarou, N., \& Tzakou, O. (2002). Composition and antifungal activity on soil-borne pathogens of the essential oil of Sal- 
via sclarea from Greece. Journal of Agricultural and Food Chemistry, 50(23), 6688-6691.

Pop, A. V., Tofana, M., Socaci, S. A., Pop, C., Rotar, A. M., Nagy, M., \& Salanta, L. (2016). Determination of antioxidant capacity and antimicrobial activity of selected Salvia species. Bulletin of University of Agricultural Sciences and Veterinary Medicine Cluj-Napoca-Food Science and Technology, 73(1), 14-18.

Raafat, K., \& Habib, J. (2018). Phytochemical compositions and antidiabetic potentials of Salvia sclarea L. essential oils. Joumal of Oleo Science, 67(8), 1015-1025.

Rozalski, M., Kuzma, L., Krajewska, U., \& Wysokinska, H. (2006). Cytotoxic and proapoptotic activity of diterpenoids from in vitro cultivated Salvia sclarea roots. Studies on the leukemia cell lines. Zeitschrift Fur Naturforschung Section C-A Journal of Biosciences, 61, 483-488.

Salehi, B., Ata, A., V Anil Kumar, N., Sharopov, F., Ramírez-Alarcón, K., RuizOrtega, A., Abdulmajid Ayatollahi, S., Tsouh Fokou, P. V., Kobarfard, F., Amiruddin Zakaria, Z., Iriti, M., Taheri, Y., Martorell, M., Sureda, A., Setzer, W. N., Durazzo, A., Lucarini, M., Santini, A., Capasso, R., Ostrander, E. A., Ur-Rahman, A., Choudhary, M. I., Cho, W. C., \& Sharifi-Rad, J. (2019). Antidiabetic potential of medicinal plants and their active components. Biomolecules, 9(10), 551.

Seol, G. H., Lee, Y. H., Kang, P., You, J. H., Park, M., \& Min, S. S. (2013). Randomized controlled trial for Salvia sclarea or Lavandula angustifolia: Differentia effects on blood pressure in female patients with urinary incontinence undergoing urodynamic examination. Journal of Alternative and Complementary Medicine, 19(7), 664-670.

Seol, G. H., Shim, H. S., Kim, P. J., Moon, H. K., Lee, K. H., Shim, I., Suh, S. H., \& Min, S. S. (2010). Antidepressant-like effect of Salvia sclarea is explained by modulation of dopamine activities in rats. Journal of Ethnopharmacology, 130(1), 187-190

Tavakkoli, M., Miri, R., Jassbi, A. R., Erfani, N., Asadollahi, M., Ghasemi, M., Saso, L., \& Firuzi, O. (2014). Carthamus, Salvia and Stachys species protect neurona cells against oxidative stress-induced apoptosis. Pharmaceutical Biology, 52(12), 1550-1557.

Tkachuk, V. G., \& Shapoval, V. V. (1987). The effect of Salvia sclarea ether oil on the immunological and enzymatic systems. Vrachebnoe Delo, 5, 83-84.

Toghyani, M., Akhavan, M. I., \& Aghdam, S. H. (2012). Effect of sage powder (Salvia officinalis L.) on serum biochemistry and immunity of broiler chicks. Reviews on Clinical Pharmacology and Drug Therapy, 10(2), 107.
Tuttolomondo, T., Iapichino, G., Licata, M., Virga, G., Leto, C., \& La Bella, S. (2020). Agronomic evaluation and chemical characterization of Sicilian Salvia sclarea L. accessions. Agronomy, 10(8), 1114.

Ulubelen, A., Topcu, G., Eris, C., Sonmez, U., Kartal, M., Kurucu, S., \& Bozokjohansson, C. (1994). Terpenoids from Salvia sclarea. Phytochemistry, 36(4), 971-974.

Vaccaro, M. C., Alfieri, M., De Tommasi, N., Moses, T., Goossens, A., \& Leone, A. (2020). Boosting the synthesis of pharmaceutically active abietane diterpenes in S. sclarea hairy roots by engineering the GGPPS and CPPS genes. Frontiers in Plant Science, 11, 924

Vaccaro, M., Bernal, V. O., Malafronte, N., De Tommasi, N., \& Leone, A. (2019). High yield of bioactive abietane diterpenes in Salvia sclarea hairy roots by overexpressing cyanobacterial DXS or DXR genes. Planta Medica, 85, 973-980.

Vega, N., \& Perez, G. (2006). Isolation and characterisation of a Salvia bogotensis seed lectin specific for the Tn antigen. Phytochemistry, 67(4), 347-355.

Vergine, M., Nicoli, F., Negro, C., Luvisi, A., Nutricati, E., Accogli, R. A., Sabena, E., \& Miceli, A. (2019). Phytochemical profiles and antioxidant activity of Salvia species from Southern Italy. Records of Natural Products, 13(3), 205-215.

Wong, J Chiang Y. F Shih, Y. H, Chiu C. H Chen, H Y, Shieh, T. M., Wang, K. L., Huang, T. C., Hong, Y. H., \& Hsia, S. M. (2020). Salvia sclarea L. essential oil extract and its antioxidative phytochemical sclareol inhibit oxytocin-induced uterine hypercontraction dysmenorrhea model by inhibiting the $\mathrm{Ca}^{2+}-\mathrm{MLCK}$ MLC20 signaling cascade: An ex vivo and in vivo study. Antioxidants, 9(10), 991.

Wu A. M. (2005). Lectinochemical studies on the glyco-recognition factors of a Tn (GalNAc alpha 1 -> Ser/Thr) specific lectin isolated from the seeds of Salvia sclarea). Journal of Biomedical Science, 12(1), 167-184.

Yang, H. J., Kim, K. Y., Kang, P., Lee, H. S., \& Seol, G. H. (2014). Effects of Salvia sclarea on chronic immobilization stress induced endothelial dysfunction in rats. BMC Complementary and Alternative Medicine, 14, 396

Zazharskyi, V. V., Davydenko, P. O., Kulishenko, O. M., Borovik, I. V., \& Brygadyrenko, V. V. (2019). Antimicrobial activity of 50 plant extracts. Biosystems Diversity, 27(2), 163-169.

Zivkovic, J., Ristic, M., Kschonsek, J., Westphal, A., Mihailovic, M., Filipovic, V., \& Bohm, V. (2017). Comparison of chemical profile and antioxidant capacity of seeds and oils from Salvia sclarea and Salvia officinalis. Chemistry and Biodiversity, 14(12), e1700344. 